\title{
EVALUATION OF SELF OSTEOMIZING IMPLANTS FOR REPLACEMENT OF MANDIBULAR POSTERIOR TEETH (CLINICAL AND RADIOGRAPHIC STUDY)
}

\author{
Riman M. Tawfik ${ }^{1 *} B D S$, Samraa A. El Sheikh² $P h D$, Hala R. Ragab ${ }^{3} P D$
}

\begin{abstract}
INTRODUCTION: Osseointegration, defined as a direct structural and functional connection between ordered living bone and the surface of a load-carrying implant, is critical for implant stability and is considered a prerequisite for implant loading and long-term clinical success of endosseous dental implants.

Primary stability following implant placement is essential for osseointegration and is mainly influenced by the following main factors density, quantity of bone at the implant site and implant design.

Moreover, implant surface topography is a key factor in the achievement of osseointegration, the most common modification of implant topography is surface roughness. This is achieved by acid etching, sandblasting, or oxidization.

OBJECTIVES: To evaluate the effectiveness of using MPM, compared to the use of bone graft alone, to assess the exact effect of each in enhancing the osteogenic differentiation and bone formation.

MATERIALS AND METHODS: This clinical study was performed on a total of eleven patients (14 implants), with missing mandibular posterior teeth indicated for implant restoration. Implants were placed according to manufacturer's instructions. After 3 months, final crowns were delivered. All implants were followed up for 6 months. Clinically, each patient was evaluated for pain, swelling and stability of the implant. Radiographically, cone beam computed tomography (CBCT) was used for the assessment of marginal bone level and bone density. RESULTS: There was a significant increase in bone density from the preoperative phase to the end of the 6 months. The mean of marginal bone level loss from the preoperative period to the 3rd month was significant as well as from the preoperative period to the 6th month. One case displayed periimplantitis and mobility in the first month of follow up and hence it was removed and regarded as failure case.

CONCLUSIONS: Self osteomizing implants are a good choice for replacing missing mandibular posterior teeth with satisfactory clinical outcomes and a low incidence of complications.

KEYWORDS: Titanium implant, self osteomizing, osseointegration, selective surface treatment, primary stability.
\end{abstract}

1. BDS, 2010, Faculty of Dentistry, Alexandria University.

2. Professor of Oral and Maxillofacial Surgery, Faculty of Dentistry, Alexandria University.

3. Assistant Professor of Oral and Maxillofacial Surgery, Faculty of Dentistry, Alexandria University

* Corresponding author:

E-mail: rimonista2@yahoo.com

\section{INTRODUCTION}

A major advance in dentistry has been the successful replacement of lost natural teeth by osseointegrated implants (1). Osseointegration is the basis of a successful endosseous implant, it is defined as a direct structural and functional connection between ordered, living bone and the surface of a load-carrying implant (2).

It involves an initial interlocking between alveolar bone and the implant body, and later, biological fixation through continuous bone apposition and remodeling toward the implant (2). Osseointegration is also a measure of implant stability, which can occur at 2 different stages: primary and secondary. Primary stability of an implant mainly comes from mechanical engagement with compact bone. Secondary stability, on the other hand, offer biological stability through bone regeneration and remodeling $(3,4)$. The former is a requirement for secondary stability. The latter, however dictates the time of functional loading (2).

There are two types of the implant design; macrodesign and microdesign. The former includes thread geometry and body shape while the latter consists of implant material and surface treatment and morphology (5).

Moreover, it was known that implants with different characteristics show different biomechanical behavior as changes in macrogeometry (tapered versus parallel-walled, thread shape, length, and diameter) and microgeometry (surface texture) lead to different insertion torque and implant stability quotient values even when inserted in the same osteotomic preparation (6).

Implants used in this study have new features in both the micro and macro design, they are surface finished using DualSelect ${ }^{\mathrm{TM}}$ technology in a two-stage geographic blasting and acid treatment process to promote osseointegration and the attachment of bone to implant surface on a microscopical level while the apical $5 \mathrm{~mm}$ of each implant is strategically protected from blast media and left machine finished to preserve its sharp cutting features.

In return this gives the implants aggressive blades (not threads) that shave the surrounding bone rather than scraping it which allows the implant to be accurately and tightly fitted in the osteotomy hence the name (self osteomizing implants).

This study aimed to evaluate bone healing around the recently developed self osteomizing implants as well as the surrounding bone density in replacing mandibular posterior teeth.

\section{MATERIALS AND METHODS}

Informed consent: All patients received explanations about the planned treatment and its potential risks and complications and signed a written informed consent form prior to being enrolled in the study. 
It was also mentioned that the patient had the right of withdrawal from the study anytime. Ethical approval for this study was obtained from the research ethics committee, Faculty of Dentistry, Alexandria University before beginning the study.

\section{Study Design}

This study was conducted on eleven patients (14 implants) in need for implant placement for their missing mandibular posterior teeth.

All patients were selected from the outpatient Clinic of Oral and Maxillofacial Surgery Department, Faculty of Dentistry, Alexandria University.

\section{Criteria for patient selection} Inclusion criteria

- The patient should be free from any relevant systemic disease (uncontrolled diabetes mellitus, uncontrolled hypertension) that is contraindicated for implant surgery or may affect bone healing.

- Patients with missing mandibular posterior teeth should have adequate bone quality and inter-occlusal space not less than $7 \mathrm{~mm}$.

- Patients should have adequate oral hygiene and periodontal condition

\section{Exclusion criteria}

- Patients with parafunctional habits.

- Heavy smokers and alcoholic patients.

\section{Materials}

\section{Implant system}

Implanova implants system (Implanova ${ }^{\circledR}$ developed by Dental Evolutions, Inc (USA)are made of Grade 23 titanuim alloy having a Dual select technology in a two stage geographic blasting and acid treating process to promote osseointegration. They are presented with a cutting-edge self-osteomizing, self-grafting design developed with CAD/CAM technology. (Figure 1)
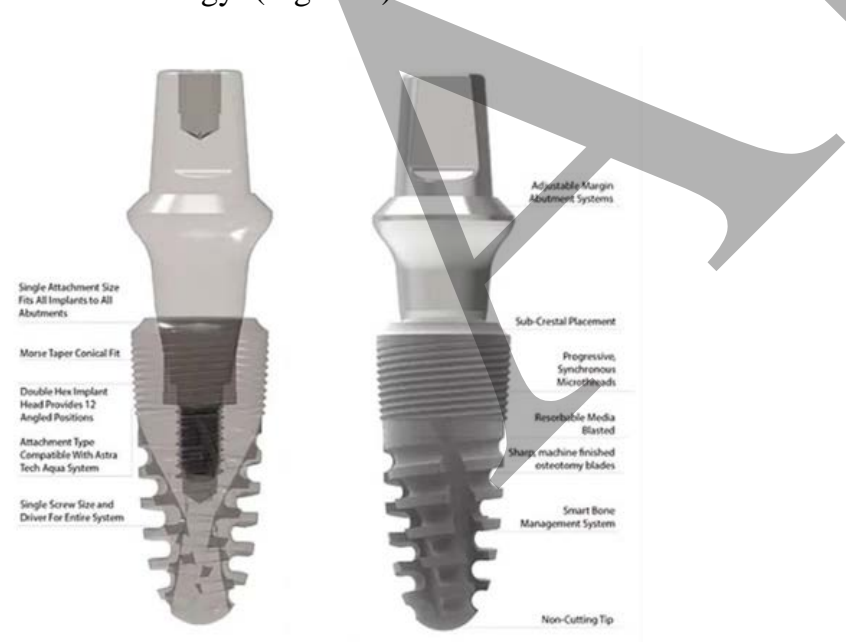

Figure (1): Implanova implant overview.

They have the following characteristics:

- Self-osteomizing aggressive blades not threads that would shave the surrounding bone rather than scraping it resulting in a perfect tight stable osteotomy.

- Self-grafting channels attributed to smart bone management system where it features deep channels with a patented negative rake angle guiding and transporting bone shavings apically which will condense and pack around the implant leading to optimal primary stability and a kick start for Osseointegration.
- The apical $5 \mathrm{~mm}$ of the implants are left machine finished, to retain its sharp cutting edges and the rest of the implants are blast finished using resorbable apatitic calcium phosphate blasting media.

- Maximum platform switching which helps minimize bone loss and allows for any type of emergence profile.

The implants used for this study were selected in two different sizes $(4.5 \times 8)(4.5 \times 10)$.

\section{Methods}

\section{I.Pre-surgical phase}

Prior to implant placement each patient was investigated clinically and radiographically. Clinical evaluation of the implant site including inspection, palpation of the edentulous alveolar ridge, the occlusion, and inter-occlusal space. Primary alginate impressions for both arches were taken and diagnostic study models were prepared. Study casts were used to evaluate the jaw relationship and the inter-occlusal space. Pre-operative cone beam computed tomography (CBCT) was done for all patients to detect any clinically undetectable pathology, important anatomical structures, bone width and implant position, angulation and depth.

\section{II.Surgical phase}

Chlorohexidine gluconate $0.12 \%$ mouth wash (Hexitol mouthwash, Arab drug company, Cairo, Egypt) was used to rinse for 30 seconds before operation. All patients were operated under local nerve block anaesthesia. Paracrestal incision was performed and full thickness mucoperiosteal flap was reflected to access the site. The implant bed was prepared using drills specific for each implant size. The sequence of drilling was carried out according to manufacturer's instructions. Tapered implants with an internal connection and selective surface treatment were inserted into the osteotomy site. The smart Peg type 38 was attached to the dental implant for measuring primary stability using Osstell ${ }^{\circledR}$ (integration Diagnostics AB, Goteborg, Sweden). A cover screw supplied with the implant was inserted on the implant with the use of implant screw driver. Suturing of the flap with interrupted sutures, using 3/0 black silk suturing material (Figure 2).

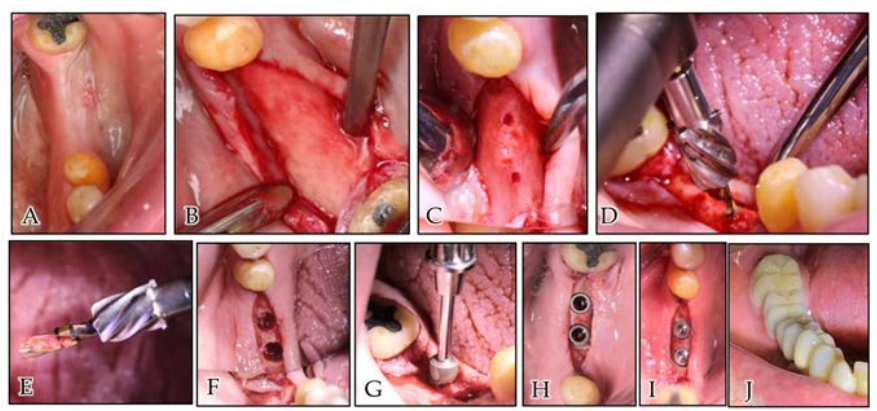

Figure (2): (A) Clinical overview, (B) Mucoperiosteal flap, (C) Marking the initial drill, (D) Drilling the bone, (E) Showing implanova drill, (F) Osteotomy site, (G) Loading the implant, $(\mathrm{H})$ Implants in place, (I) Cover screw, (J) Final prosthesis.

\section{III.Post-surgical phase}

1. Postoperative instructions including: cold application to the surgical site extraorally by using a cold pack or an ice bag intermittently for 20 minutes on and 20 minutes off during the first 24 hours to minimize postoperative edema and swelling and maintain daily routine oral hygiene after surgery and patients were instructed to eat a soft diet for 7 days. 
2. All patients received postoperative medications including:

- Broad-spectrum oral antibiotics: Amoxicillin $875 \mathrm{mg} /$ Clavulanic acid 125mg (Augmentin 1gm Tablets, Medical Union Pharmaceuticals (MUP), GlaxoSmithKline, Cairo, Egypt) every 12 hours for five days.

- Non-steroidal anti-inflammatory drugs Ibuprofen $400 \mathrm{mg}$ (Brufen tablet 400 mg Abbott, Cairo, Egypt) every eight hours for four days.

3. A digital periapical x-ray was taken immediately after implant placement and the sutures were removed after one week postoperatively.

\section{IV.Post-operative evaluation}

\section{I.Clinical evaluation}

- Patients were evaluated clinically at interval of 7 days 1,3,6 months postoperatively for presence of pain using the Visual Analogue scale (VAS) (7), Presence of Swelling or infection and implant stability. The implant stability measurement was examined immediately at the time of implant insertion and at 3 months postoperatively using the Resonance Frequency Analysis via the Osstell ISQ system (Osstell ${ }^{\circledR}$, integration Diagnostics AB, Goteborg, Sweden).

\section{II.Radiographic evaluation (Figure 3)}

- Cone beam computed tomography (CBCT) (i-CAT Next Generation (Imaging Sciences International, Hatfield, PA, USA) was obtained pre-operatively, 3 months and 6 months postoperatively to assess:

\section{Bone density around the implant}

- Measurement of the bone density of the newly formed bone using cone beam computed tomography (CBCT) software OnDemand3Dtm to evaluate radiographic bone density apical to each implant. “Ondemand 3D” (Cybermed, Korea) version 1.0.7. Measurements were taken as follows:

- The bone density apical, buccal and lingual to the implant was used as a known measurement in Hounsfield Unit (HU).

- Mean, standard deviation, minimum and maximum readings were automatically displayed by the system.
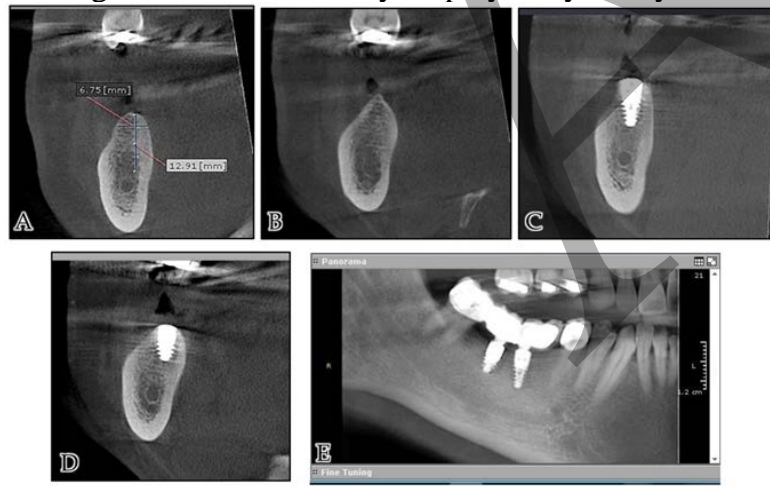

Figure (3): Preoperative CBCT coronal view showing: (A) Missing mandibular first molar. (B) Missing mandibular second molar. Three months postoperative CBCT coronal view showing (C) implant placed at mandibular right first molar (D) implant placed at mandibular right second molar. (E) 6 months CBCT panoramic view after final restoration.

\section{Marginal bone level}

- Marginal bone level is defined as the distance between a reference point (implant shoulder) and the first marginal bone to implant contact level (8-10).

- Marginal bone level was determined on both mesial and distal implant surfaces using the linear measurement system supplied by the specially designed software (OnDemand 3D)

- Mean, standard deviation, minimum and maximum readings were automatically displayed by the system.

\section{V.Prosthetic phase}

After 3 months, the cover screw was removed and the healing abutment was tightened. After 2 weeks, the healing abutment was removed and the final abutment was tightened and definitive porcelain fused to metal restoration was delivered to all patients

\section{Statistical analysis}

Data were fed to the computer and analyzed using IBM SPSS software package version 20.0 (11) (Armonk, NY: IBM Corp). Quantitative data were described using range, mean, standard deviation and median. The distribution of quantitative variables was tested for normality using Kolmogorov-Smirnov test. The paired t- test was used to compare between two periods showing normally distributed quantitative variables, while the ANOVA with repeated measures was used to compare between more than two periods or stages, and Bonferroni Post Hoc test. The Friedman test was used for abnormally distributed quantitative variables, with Dunn's Post Hoc Test. Significance of the obtained results was judged at the 5\% level.

\section{RESULTS}

Eleven patients (6 male and 5 female) with missing mandibular posterior teeth indicated for implant placement were evaluated in this study. Their ages ranged from 20 to 40 years. Fourteen implants were placed. Eight patients received single implant while the remaining 3 cases each received two implants with a total of 8 implants with 4,5 mm diameter X $10 \mathrm{~mm}$ length and 6 implants with 4,5 mm diameter X $8 \mathrm{~mm}$ length. Implants were used to restore missing mandibular first and /or second molars.

All patients were followed up for six months and the results were registered as regards: clinical evaluation and radiographic evaluation.

\section{Clinical evaluation}

1. Presence of pain: Pain was evaluated daily for one week using visual analogue scale (VAS) (7) from 0 to 10 ("0" is pain free and "10" is unbearable pain). After surgery, eight patients experienced mild pain (VAS=2-4) and three patients experienced moderate pain (VAS $=5-7$ ), at surgical site for 1-3 days duration.

2. All patients continued the follow up period without any signs of infection, gingivitis or swelling except in one case, where peri-implant infection and mobility was found during the 1st month of follow up and implant was removed.

3. Implant stability quotient (ISQ) was measured by Ostell (Table 1, Figure 4). The mean implant stability quotient at day of surgery was $65.64 \pm 5.05$. There was an increase in 3rd month post-71.14 \pm 4.09 . The increase in implant stability quotient in three months was statistically significant. 


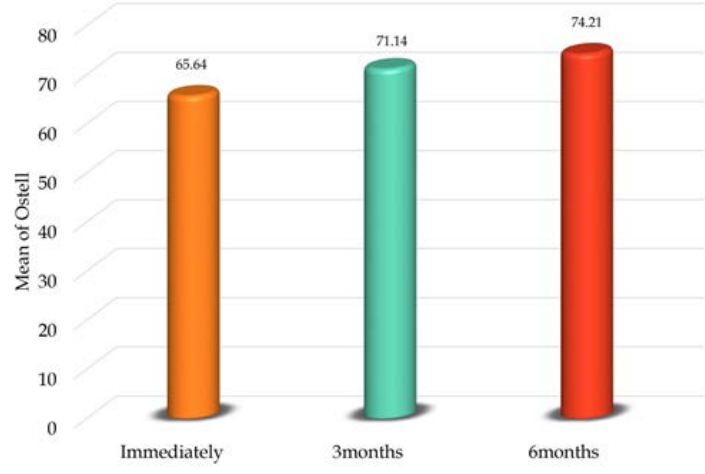

Figure (4): Comparison between the three studied periods according to evaluation of primary implant stability.

Table (1): Comparison between the three studied periods according to evaluation of primary implant stability

\begin{tabular}{|c|c|c|c|c|c||}
\hline $\begin{array}{c}\text { Evaluation of } \\
\text { primary } \\
\text { implant } \\
\text { stability }\end{array}$ & $\begin{array}{c}\text { Immediatel } \\
\mathbf{y} \\
(\mathbf{n}=\mathbf{1 4})\end{array}$ & $\begin{array}{c}\text { 3months } \\
(\mathbf{n = 1 4 )}\end{array}$ & $\begin{array}{c}\mathbf{6 m o n t h s} \\
\mathbf{( n = 1 4 )}\end{array}$ & $\mathbf{F}$ & $\mathbf{p}$ \\
\hline Min. - Max. & $54.0-73.0$ & $62.0-79.0$ & $63.0-81.0$ & & \\
Mean \pm SD. & $65.64 \pm 5.05$ & $71.14 \pm 4.09$ & $74.21 \pm 5.39$ & $52.824^{*}$ & $<0.001^{*}$ \\
Median & 67.50 & 72.0 & 74.50 & & \\
\hline $\begin{array}{l}\text { Sig. bet. } \\
\text { periods }\end{array}$ & \multicolumn{2}{|c||}{$\mathrm{p}_{1}<0.001^{*}, \mathrm{p}_{2}<0.001^{*}, \mathrm{p}_{3}=0.007^{*}$} & & \\
\hline
\end{tabular}

F: F test (ANOVA) with repeated measures, Sig. bet. periods was done using Post Hoc Test (Bonferroni)

$\mathrm{p}$ : $\mathrm{p}$ values for comparison between the three studied periods $\mathrm{p}_{1}$ : $\mathrm{p}$ values for comparing between Immediate and 3months p2: p values for comparing between Immediate and 6months pз: $p$ values for comparing between 3months and 6 months

*: Statistically significant at $\mathrm{p} \leq 0,05$

\section{Radiographic Evaluation:}

\section{Bone density}

Data were collected regarding mean peri-implant bone density values, standard deviation and percentage of change at preoperative, 3 months and 6 months. (Tables 2, Figure 5)

Table (2): Comparison between the three studied periods according to bone density around the implant

\begin{tabular}{|c|c|c|c|c|c|}
\hline $\begin{array}{l}\text { Bone density } \\
\text { around the } \\
\text { implant }\end{array}$ & \begin{tabular}{|c|}
$\begin{array}{c}\text { Preoperati } \\
\text { ve } \\
(n=14)\end{array}$ \\
\end{tabular} & $\begin{array}{c}\text { 3months } \\
(n=14)\end{array}$ & $\begin{array}{c}\text { 6months } \\
(n=14)\end{array}$ & $F$ & $\mathbf{p}$ \\
\hline $\begin{array}{l}\text { Min. - } \\
\text { Max. }\end{array}$ & $\begin{array}{c}690.7- \\
1114.0\end{array}$ & $\begin{array}{c}1009.5- \\
1575.6\end{array}$ & $\begin{array}{l}915.8- \\
1643.1\end{array}$ & & \\
\hline $\begin{array}{l}\text { Mean } \pm \\
\text { SD. }\end{array}$ & $\begin{array}{c}903.6 \pm \\
121.4\end{array}$ & $\begin{array}{c}1236.1 \pm \\
185.9\end{array}$ & $\begin{array}{c}1325.4 \pm \\
189.4\end{array}$ & $31.527^{*}$ & $<0.001^{*}$ \\
\hline Median & 887.5 & 1214.6 & 1367.9 & & \\
\hline $\begin{array}{l}\text { Sig. bet. } \\
\text { Periods }\end{array}$ & \multicolumn{3}{|c|}{$\mathrm{p}_{1}<0.001^{*}, \mathrm{p}_{2}<0.001^{*}, \mathrm{p}_{3}=0.494$} & & \\
\hline
\end{tabular}

F: F test (ANOVA) with repeated measures, Sig. bet. periods was done using Post Hoc Test (Bonferroni)

$\mathrm{p}$ : $\mathrm{p}$ values for comparison between the three studied periods $\mathrm{p}_{1}$ : $\mathrm{p}$ values for comparing between preoperative and 3months $\mathrm{p}_{2}$ : $\mathrm{p}$ values for comparing between preoperative and 6months $\mathrm{p}_{3}$ : $\mathrm{p}$ values for comparing between 3months and 6 months

*: Statistically significant at $\mathrm{p} \leq 0.05$

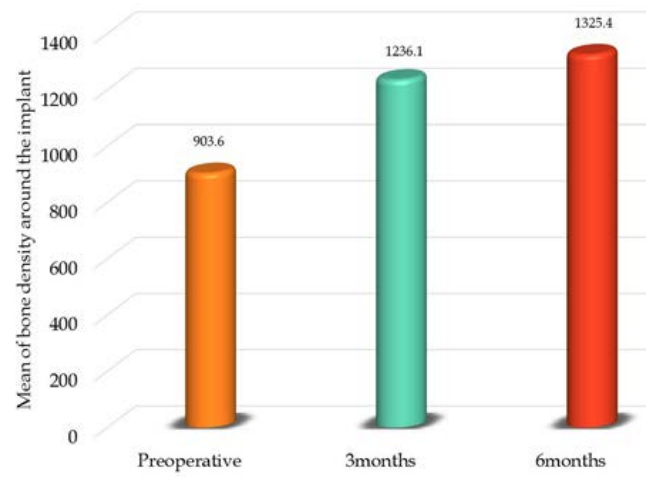

Figure (5): Comparison between the three studied periods according to bone density around the implant.

In the preoperative phase, the mean peri-implant bone density was 903.6 $\pm 121.4 \mathrm{HU}$ with a minimum recorded value of $690.7 \mathrm{HU}$ and a maximum recorded value of $1114.0 \mathrm{HU}$.

In the third month, the mean peri-implant bone density was $1236.1 \pm 185.9 \mathrm{HU}$ with a minimum recorded value of 1009. HU and a maximum recorded value of $1575.6 \mathrm{HU}$. In the sixth month, the mean peri-implant bone density was 1325.4 \pm 198.4 HU with a minimum recorded value of 915.8HU and a maximum recorded value of 1643.1 HU. These differences were statistically significant $(\mathrm{p}<0.05)$.

\section{Marginal bone level}

Data were collected regarding the marginal bone level at the mesial and distal aspects of all implants at preoperative, 3 months and 6 months period.

The data collected was tabulated and the statistical analysis of the marginal bone level scores was done for all patients. (Tables 3, Figure 6)

Table (3): Comparison between the three studied periods according to marginal bone level around the implants

\begin{tabular}{|r|c|c|c|c|c||}
\hline $\begin{array}{c}\text { Marginal bone } \\
\text { level around } \\
\text { the implants }\end{array}$ & $\begin{array}{c}\text { Preoperativ } \\
\mathbf{e} \\
(\mathbf{n}=\mathbf{1 4})\end{array}$ & $\begin{array}{c}\text { At 3months } \\
\mathbf{( n = 1 4 )}\end{array}$ & $\begin{array}{c}\text { At 6months } \\
(\mathbf{n = 1 4 )}\end{array}$ & $\mathbf{F}$ & $\mathbf{p}$ \\
\hline Min. - Max. & $8.0-10.0$ & $7.0-9.70$ & $6.87-9.18$ & & \\
Mean \pm SD. & $9.14 \pm 1.03$ & $8.41 \pm 1.07$ & $8.19 \pm 0.98$ & $29.536^{*}$ & $<0.001$ \\
Median & 10.0 & 8.30 & 8.89 & & \\
\hline $\begin{array}{c}\text { Sig. bet. } \\
\text { periods }\end{array}$ & \multicolumn{2}{|c|}{$\mathrm{p}_{1}=0.002^{*}, \mathrm{p}_{2}<0.001^{*}, \mathrm{p}_{3}=0.464$} & & \\
\hline
\end{tabular}

F: F test (ANOVA) with repeated measures, Sig. bet. periods was done using Post Hoc Test (Bonferroni) $\mathrm{p}$ : $\mathrm{p}$ values for comparison between the three studied periods $\mathrm{p}_{1}$ : $\mathrm{p}$ values for comparing between preoperative and 3months p2: $p$ values for comparing between preoperative and 6months $\mathrm{p}_{3}$ : $\mathrm{p}$ values for comparing between 3months and 6 months *: Statistically significant at $\mathrm{p} \leq 0.05$ 


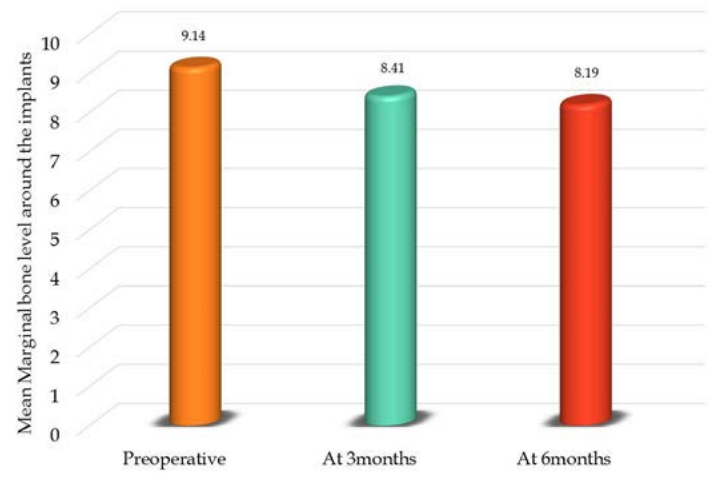

Figure (6): Comparison between the three studied periods according to marginal bone level around the implants.

In the preoperative phase, the mean marginal bone level (MBL) value was $9.14 \pm 1.03 \mathrm{~mm}$ with a minimum-recorded value of $8.0 \mathrm{~mm}$ and a maximum-recorded value of 10.0 $\mathrm{mm}$.

In the third month, the mean MBL value was $8.41 \pm 1.07$ mm with a minimum-recorded value of $7 \mathrm{~mm}$ and a maximum-recorded value of $9.70 \mathrm{~mm}$.

In the sixth month, the mean $\mathrm{MBL}$ value was $8.19 \pm 0.98 \mathrm{~mm}$ with a minimum-recorded value of $6.87 \mathrm{~mm}$ and a maximum-recorded value of $9.18 \mathrm{~mm}$. These differences were statistically significant $(\mathrm{p}<0.05)$.

\section{DISCUSSION}

In accordance with their increased success rate, dental implants have become a popular treatment option for missing teeth. Bone density and implant stability are important factors for implant osseointegration and hence implant success which has been widely demonstrated by several authors (12). However, implants are frequently associated with post restorative crestal bone level alterations of about 1 to $2 \mathrm{~mm}$ during the first year of loading. As a consequence, an implant is defined as successful only when the peri-implant bone loss does not exceed $2 \mathrm{~mm}$ in the first year of function and remains less than $0.2 \mathrm{~mm}$ annually thereafter (13).

Therefore, this present study was conducted on 11 patients with missing mandibular posterior teeth to assess implant stability as well as the clinical and radiographic bone response to implants with modified design and surface treatment features. Regarding patients' selection, all patients in this study were free from any uncontrolled systemic diseases or conditions that may impose a risk factor for implant success and therefore needs special precautions to be taken (14).

Also patients in this study were non-smokers, the reason behind this is that smoking interferes with wound healing, irritates the soft tissue and is also associated with bone loss thus delays healing (15).

Implants used in this study were characterized by special features such as the progressive self osteomizing threads which are attributed to the good primary stability at the time of insertion.

This agreed with a study done by Ruiz et al in (2016) (16) which concluded that the effects of the progressive threads were beneficial for primary stability, as they provide better mechanical anchorage in the surrounding bone and higher bone to implant contact ratio.

Primary stability of implants is known to be dependent on several factors: material, surface treatment, diameter, and shape of the dental implant itself as well as practical factors during the surgery (17-19).

Implants used are surface finished using dual select technology in a two stage geographic blasting and acid treating process to promote osseointegration.

This was proven by Jemat et al in 2015 (20) where he favoured surface treatment of dental implants via coating and acid etching over other methods in producing good substrate surfaces for osseointegration, with surface roughness ranging from 0.44 to $8.68 \mu \mathrm{m}$. In short, a good surface with the right roughness and mechanical properties could lead to better osseointegration for successful dental implants. During preparation of the osteotomy site, a reduced diameter drill was selected to increase the primary stability during final insertion. So, the implant was press fitted into the site while loading. This press-fit theory emphasizes, that accuracy is a fundamental resource needed to achieve primary stability and successful outcome (2124). Markovic et al (25) in 2011 evaluated primary implant stability in self tapping and non self tapping dental implants and found that significantly higher stability was shown by self-tapping implants. After bone drilling, self-tapping implants achieved significantly higher stability than nonself-tapping implants during the entire follow-up period. Regarding surgical protocol for implant placement, conventional flap surgery was used; the surgery was carried out in two phases (Submerged). The implant was surgically placed and covered with the gingival tissue for a healing period ranging from 3-4 months. Later on, another surgery was required and the healing cap was screwed into the implant which allowed the soft tissue to heal around it. Two weeks after the second surgery, the prosthetic phase took place this allowed better healing and avoided infection.

In the present study, the implant stability was measured using the Resonance Frequency Analysis (RFA) via the Osstell ISQ system immediately, 3 and 6 months postoperative. RFA was chosen as a non-invasive and reliable method to assess variation in implant stability over time. ISQ values increased significantly over time and towards the sixth month. RFA registrations are directly related to the stiffness of the implant in the surrounding bone: during healing an increase in implant stability quotient (ISQ) values presumably reflect new bone apposition at the implant-bone interface (24).

Regarding the mean bone density, it increased significantly towards the six month post-operatively. This could be credited to the healing of the bone around implants. These results were in agreement with the results of AlSudani in 2014 (26) who studied twenty implants in the premolar and molar region of both maxilla and mandible by using CBCT evaluation and measured the bone density by using $\mathrm{HU}$ around them and concluded that the bone density increased with osseointegration towards the 6th month, the increasing rate of bone density could be determined by quality of jaw bone before, and after implant insertion.

The used implants were characterized by maximum platform switch which was proven to aid in minimizing marginal bone loss and preserves peri-implant bone. (27)

This was evidenced by the statistically significant decrease in the mean of peri-implant bone level towards the sixth month found in our study. This matched to the study done by Jung et al in 2012 (28) and Galindo Moreno et al in 2015 (29), who stated that despite the excellent survival rates of dental implants, long term studies have shown 1.5 
to $2 \mathrm{~mm}$ of bone loss around the neck of the implant during the first year of functional loading and an annual rate of marginal bone loss (MBL) around $0.2 \mathrm{~mm}$, after the first year.

\section{CONCLUSION}

Within the limits of this study, the conclusion that can be drawn from this study is that the use of self osteomizing implants for replacing mandibular posterior teeth has been a highly successful procedure with satisfactory clinical outcomes and low incidence of complications.

\section{CONFLICT OF INTEREST}

The authors declare that they have no conflicts of interest.

\section{REFERENCES}

1-Jayesh RS, Dhinakarsamy V. Osseointegration J. Pharm Bioallied Sci. 2015;7(Suppl 1):S226-S9.

2-Parithimarkalaignan S, Padmanabhan TV. Osseointegration: An Update. J Indian Prosthodont Soc. 2013;13:2-6.

3-Natali AN, Carniel EL, Pavan PG. Investigation of viscoelastoplastic response of bone tissue in oral implants press fi t process. J Biomed Mater Res B Appl Biomater. 2009;91:868-75.

4-Greenstein G, Cavallaro J, Romanos G, Tarnow D. Clinical recommendations for avoiding and managing surgical complications associated with implant dentistry: A review. J Periodontol. 2008;79:1317-29.

5-Chrcanovic BR, Albrektsson T, Wennerberg A. Reasons for failures of oral implants. J Oral Rehabil. 2014;41:443-76.

6-Baldi D, Lombardi T, Colombo J, Cervino G, Perinetti G, Di Lenarda R, et al. Correlation between Insertion Torque and Implant Stability Quotient in Tapered Implants with Knife-Edge Thread Design. Biomed Res Int. 2018;2018:7201093.

7-McCormack HM, David Jdl, Sheather S. Clinical applications of visual analogue scales:a critical review. Psychol Med 1988;18:1007-19.

8-Dias DR, Leles CR, Lindh C, Riberio - Rotta RF. The effect of marginal bone level changes on the stability of dental implants in a short-term evaluation. Clin Oral Implants Res. 2015;26:1185-90.

9-Burtscher D, Norer B, Dalla Torre D, Beier U, Schubert K, Grunert I. A 7-year prosoective radiographic evaluation of marginal bone level around two different implant systems: a randomized clinical trial. Clin Oral Implants Res. 2015;261244-9.

10-Berberi AN, Sabbagh JM, Aboushelib MN, Noujein ZF, Salameh ZA. A 5-year comparison of marginal bone level following immediate loading of single tooth implants placed in healed alveolar ridges and extraction sockets in the maxilla. Front Physiol. 2014:5;29.

11-Kirkpatrick LA, Feeney BC. A simple guide to IBM SPSS statistics for version 20.0. Student ed. Belmont, Calif: Wadsworth, Cengage Learning; 2013.

12-Gaviria L, Salcido JP, Guda T, Ong JL. Current trends in dental implants. J Korean Assoc Oral Maxillofac Surg. 2014;40:50-60.

13-Fickl S, Zuhr O, Stein JM, Hürzeler MB. Peri-implant bone level around implants with platform switched abutments. Int J Oral Maxillofac Implants. 2010;25:577-81.
14-Vissink A, Spijkervet F, Raghoebar GM. The medically compromised patient: Are dental implants a feasible option? Oral Dis. 2018;24:253-60.

15-Kandasamy B, Kaur N, Tomar GK, Bharadwaj A, Manual L, Chauhan M. Long-term Retrospective Study based on Implant Success Rate in Patients with Risk Factor: 15-year Follow-up. J Contemp Dent Pract. 2018;19:90-3.

16-Ruiz RAD, guirado JLC, de Val JEM, Moreno GG. Primary stability of dental implants with different thread geometries placed by clinicians with different clinical experience: An in vitro study. J Oral Science Rehabilitation. 2016;2:48-55.

17-Kim SK, Lee HN, Choi YC, Heo SJ, Lee CW, Choie MK. Effects of anodized oxidation or turned implants on bone healing after using conventional drilling or trabecular compaction technique: histomorphometric analysis and RFA. Clin Oral Implants Res. 2006;17:644-50.

18-Sennerby L. Dental implants: matters of course and controversies. Periodontol 2000. 2008;47:9-14.

19-Friberg B, Ekestubbe A, Sennerby L. Clinical outcome of Branemark System implants of various diameters: a retrospective study. Int $\mathrm{J}$ Oral Maxillofac Implants. 2002;17:671-7.

20-Jemat A, Ghazali MJ, Razali M, Otsuka Y. Surface Modifications and Their Effects on Titanium Dental Implants. Biomed Res Int. 2015;2015:791725.

21-Frisardi G, Barone S, Razionale AV, Paoli A, Frisardi F, Tullio A, et al. Biomechanics of the press-fit phenomenon in dental implantology: an image-based finite element analysis. Head Face Med. 2012;8:18.

22-Alghamdi H, Anand PS, Anil S. Undersized implant site preparation to enhance primary implant stability in poor bone density: a prospective clinical study. J Oral Maxillofac Surg. 2011;69:e506-12.

23-Anitua E, Alkhraisat MH, Pinas L, Orive G. Efficacy of biologically guided implant site preparation to obtain adequate primary implant stability. Ann Anat. 2015;199:9-15.

24-Coelho PG, Marin C, Teixeira HS, Campos FE, Gomes JB, Guastaldi F, et al. Biomechanical evaluation of undersized drilling on implant biomechanical stability at early implantation times. J Oral Maxillofac Surg. 2013;71:e69-75.

25-Marković A, Calvo-Guirado JL, Lazić Z, Gómez-Moreno G, Ćalasan D, Guardia J, et al. Evaluation of Primary stability of Self Tapping and Non Self tapping Dental Implants.A12 week Clinical study. Clin Implant Dent Relat Res. 2013;15:341-9.

26-Al-Sudani RJ. Assessment of bone density after six months from dental implants placement using computed tomography. J Baghdad Coll Dent. 2014;26:126-8.

27-De Almeida FD, Carvalho AC, Fontes M, Pedrosa A, Costa R, Noleto JW, et al. Radiographic evaluation of marginal bone level around internal-hex implants with switched platform: a clinical case report series. Int J Oral Maxillofac Implants. 2011;26:587-92.

28-Jung RE, Zembic A, Pjetursson BE, Zwahlen M, Thoma DS. Systematic review of the survival rate and the incidence of biological, technical, and aesthetic complications of single crowns on implants reported in longitudinal studies with a mean follow-up of 5 years. Clin Oral Implants Res. 2012;23(Suppl 6):2-21.

29-Galindo-Moreno P, Leon-Cano A, Ortega-Oller I, Monje A, F OV, Catena A. Marginal bone loss as success criterion in implant dentistry: beyond $2 \mathrm{~mm}$. Clin Oral Implants Res. 2015;26:e28-e34. 